\title{
Effect of Zn Interlayer Particles on Mechanical Properties and Microstructure of Friction Stir Spot Welding Aluminum Alloy
}

\author{
Lingga Arti Saputra ${ }^{1,1,}$ Nurul Muhayat ${ }^{2}$, and Triyono ${ }^{1}$ \\ ${ }^{1}$ Graduate School of Mechanical Engineering, Sebelas Maret University, Surakarta, Indonesia
}

\begin{abstract}
Global warming can be reduced by controlling emissions in motor vehicles. Lightweight aluminum materials can lower the engine work so as to reduce fuel consumption. The effect of dwell time on mechanical properties and microstructure friction stir spot welded AA1100 with particle interlayer $\mathrm{Zn}$ were investigated. The result shows that the particle interlayer $\mathrm{Zn}$ affect to the mechanical properties. The tensile shear load friction stir spot welded AA1100 with particle interlayer $\mathrm{Zn}$ is higher than hart of without particle interlayer $\mathrm{Zn}$. In line with tensile shear load that the hardness of friction stir spot welded Al with particle interlayer $\mathrm{Zn}$ got the higher hardness than of without particle interlayer $\mathrm{Zn}$. The addition of particle interlayer $\mathrm{Zn}$ reduce the hook defect and spread in the aluminum matrix as solid solution.
\end{abstract}

\section{Introduction}

Global warming can be controlled by reducing the amount of emissions in vehicles[1-3]. The use of lighter and stronger materials is one of method to improve fuel efficiency[4-5]. Welding aluminum material using a resistance spot welding (RSW) on the vehicle frame has many shortcomings. For example, the costs that used to be quite expensive, joint strength is low[6]. Kawasaki developed the method of welding friction is a single point of Friction Stir Join (SFJ) and Friction Stir Spot Welding (FSSW) [7]. FSSW is one of the development of Friction Stir Welding (FSW) process using a system where the friction[7]. FSSW which has the characteristics of solid-state properties that have many advantages over traditional fusion welding techniques[8]. for example, the welding process easier, a low porosity level, is a mechanical joint, can be used for different materials, weight reduction joint, welding low energy and produce less pollution[9].

FSSW can save $90 \%$ energy and can save the useof $40 \%$ work tools of RSW and RW[10]. FSSW problems began when their decreased ability hooking joint because there are defects[11-14]. Hooking defects can be solved by adding a second interlayer on the surface[15]. Use of $\mathrm{Zn}$ interlayer can eliminate hook defects, ICM formation, and grain size changes thereby strengthening the joint[16-18]. Interlayer $\mathrm{Zn}$ can be diffused to form structures eutectoid significantly improve the joint[19]. Use of the tool is very influential in the formation of a weld and hook defects[20-22]. Hook defects not completely lost the use pinless tool, but it can increase the usage of the cylinder pin joint and fix defects hook formation[23-24]. Therefore, this study will examine the use of aluminum

\footnotetext{
${ }^{1}$ Corresponding author: linggalampu@gmail.com
} 
welding FSSW on the addition of $\mathrm{Zn}$ in the form of particles with the interlayer parameters influence dwell time, welding depth with the use of the pin on the tool size variations shoulder.

\section{Experimental}

Aluminum material with a thickness of $1.6 \mathrm{~mm}$. materials with chemical composition $0.12 \% \mathrm{Si}, \quad 0.4963 \% \mathrm{Fe}, 0.099 \% \mathrm{Cu}, 0.1265 \% \mathrm{Mg}, 0.2001 \% \mathrm{Zn}, 0.0159 \% \mathrm{Ti}, 0.001 \% \mathrm{Cr}$, $0.0005 \% \mathrm{Ni}, 0,0191 \% \mathrm{~Pb}, 0,0055 \% \mathrm{Sn}, 98,78 \% \mathrm{Al}$. Interlayer using pure $\mathrm{Zn}$ particles with a thickness of $0.2 \mathrm{~mm}$. Fig. 1 shows the use of pure $\mathrm{Zn}$ interlayer particles of $0.2 \mathrm{~mm}$ thickness. Fig.2a Shows the process of placing the $\mathrm{Zn}$ particles by using the stopper tool. Fig.2b $\mathrm{Zn}$ interlayer particles have been composed. Fig.2c shows the FSSW welding process. The use of welding tools has the diameter of solder $10 \mathrm{~mm}$ and $2 \mathrm{~mm}$ pin diameter. Use of dwell time parameter variation for 20, 30, 40, 50s. FSSW welding specimen with length $125 \mathrm{~mm} \times$ wide $40 \mathrm{~mm}$. After the specimen is welded, then cut to see metallographic using Keller's reagent ( $4 \mathrm{ml} \mathrm{HF}, 6 \mathrm{ml} \mathrm{HCl}, 10 \mathrm{ml} \mathrm{HNO}_{3}, 180 \mathrm{ml} \mathrm{H}_{2} \mathrm{So} 4$ ). Violence value is done by using Micro Vickers using ASTM E384 standard. Tensile/shear load (Universal testing machine). Macrostructure (Olympus/ SZ 1145) scanning electron microscope (SEM, Phenom ProX) energy dispersion spectrometer (EDS). X-ray diffraction (XRD, Shimadzhu 7000).
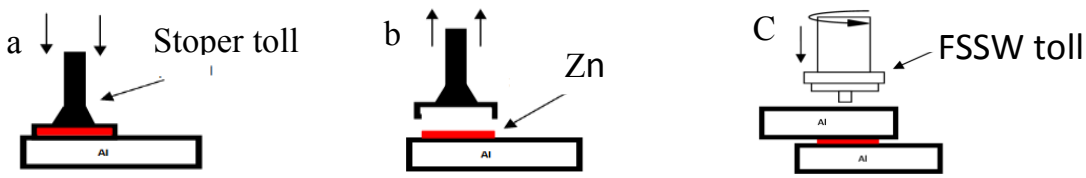

Fig.1. Position placement of $\mathrm{Zn}$ interlayer: (a) stopper tool $\mathrm{Zn}$ interlayer (b) position $\mathrm{Zn}$ particle interlayer (c) welding process

\section{Results and discussion}

\subsection{Mechanical properties and macrostructure of FSSW joints without the addition of $\mathrm{Zn}$ interlayer}

Fig.2 Show FSSWjoint without using Zn particle interlayer. On the surface of the joint there is no flow of $\mathrm{Zn}$ particles. Using pins on the tool can fix the joint [24-25]. But still looks hook defect formed around the joint area. Fig.4 is the results of the shear tensile testing for the FSSW joint and without the use of a $\mathrm{Zn}$ particle interlayer. The highest result of tensile test of FSSW without using $\mathrm{Zn}$ interlayer particles has a value of $2.7 \mathrm{kN}$ at dwell time $20 \mathrm{~s}$ with the lowest value of $2.4 \mathrm{kN}$ at dwelling time $50 \mathrm{~s}$. Fig.3 Hardness on the surface of the marked joint. Starting point of testing starts from center key hole. Distribution of penetration is the same in every variation. Profile of hardness level distribution with $\mathrm{W}$ shape [26]. Hardness value on each part shows a varied result. The highest hardness value was $46.8 \mathrm{HV}$ in the $\mathrm{SZ}$ region.
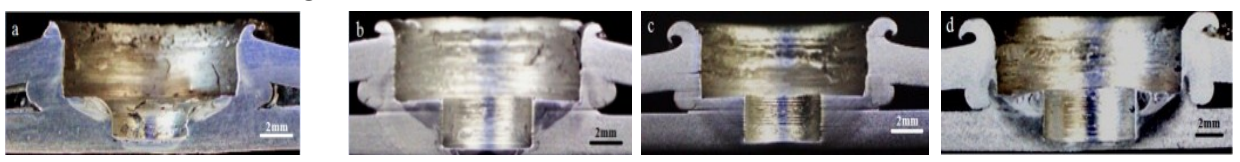

Fig 2. Mackrostruktur of FSSW without the $\mathrm{Zn}$ interlayer $10 \mathrm{~mm}(\mathrm{a} .10, \mathrm{~b} .20, \mathrm{c} .40 \mathrm{~s}, \mathrm{~d} 50 \mathrm{~s})$

\subsection{Mechanical properties and microstructure of FSSW joints with the addition of $\mathbf{Z n}$ interlayer}

3.2.1. Mechanical properties

3.2.1.1. Tensile/shear test 
Fig.4 showed tensile / shear load in joint without $\mathrm{Zn}$ interlayer particlesand with $\mathrm{Zn}$ Interlayer particlesFSSW.The addition of FSSW Zn Interlayer particles has a higher tensile / shear load than with Zn Interlayer FSSW particles. An increase in dwell time having results different each variations with Zn Interlayer particles FSSW tensile / shear load highest $3.8 \mathrm{kN}$ in dwell time $20 \mathrm{~s}$ and tensile / shear load lowest $3.1 \mathrm{kN}$ in dwell time $50 \mathrm{~s}$. Without $\mathrm{Zn}$ interlayer particlesFSSW tensile / shear load highest $2.7 \mathrm{kN}$ in dwell time $20 \mathrm{~s}$ and tensile / shear load lowest $2.4 \mathrm{kN}$ in dwell time $50 \mathrm{~s}$. FSSW welding with $\mathrm{Zn}$ Interlayer particlesas a whole provides better joint results than without $\mathrm{Zn}$ interlayer particles[25,3, 27].

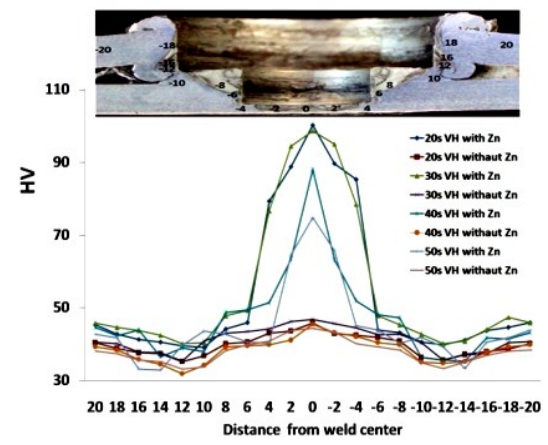

Fig 3. Microhardness of the FSSW with interlayer and without interlayer

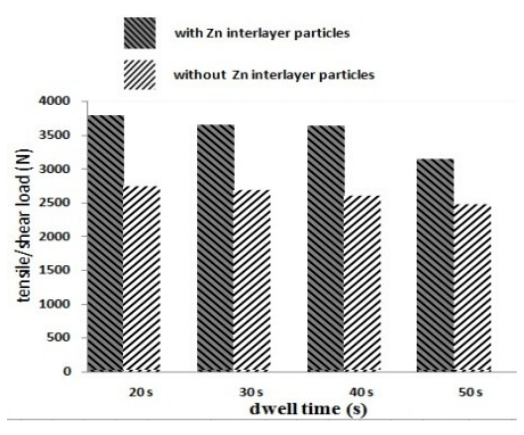

Fig 4. Tensile-shear loads of FSSW

\subsubsection{Hardness test}

Fig.3 overall FSSW with Zn particle interlayer has the highest hardness value of 100.3HV. While the FSSW without Zn interlayer particles only has the highest score of $46.8 \mathrm{HV}$. The $\mathrm{SZ}$ area is the hardest point. Hardness values begin to decrease in the HAZ area and reach the minimum value between HAZ and TMAZ. The value of hardness rises again in the SZ region[14].
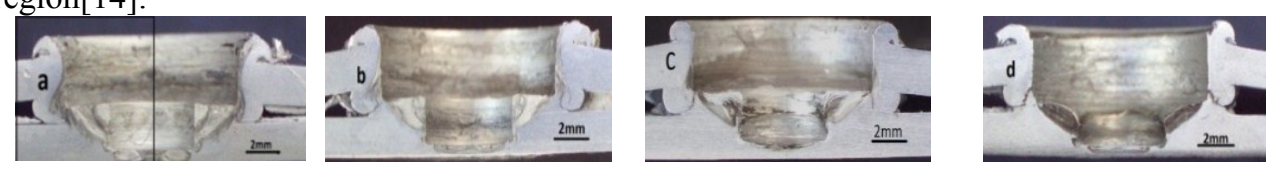

Fig 5. Mackrostruktur of FSSW with the Zn interlayer 10mm (a.10s, b.20s, c.40s, d.50s)

\subsection{Microstructure of FSSW Al alloy joints with the addition of without $\mathrm{Zn}$ interlayer particles}

Microstructure testing is performed to determine the symptoms that arise during the welding process. Fig.5 shows the difference in dwell time. the mechanical process of welding produces a hot input. Material flow is formed between substrate $\mathrm{Al}$ with $\mathrm{Zn}$ thus affecting the result of joint[26]. Fig.5 shows the variation of FSSW joint by using Zn particle interlayer. Fig4.a. shows the state of the joint between Al material and the $\mathrm{Zn}$ particle interlayer. $\mathrm{Zn}$ particles with $\mathrm{Al}$ form a reaction zone on the surface of the joint. Fig 6.a flow of $\mathrm{Zn}$ material in the nugget area appears dominant. Material flow formed due to extrusion process. This process occurs because the pin penetration force pushes the material back toward the toll and rotate the toll that stirs the material [28-29]. Fig.6.b shows mapping areas that have different views.

$\mathrm{Zn}$ particles are seen scattered around the joint region [16, 20]. The flow of $\mathrm{Zn}$ particles has a tendency to move away from the center of the mortar due to the centrifugal effect. Fig.7.(d). analysis with EDS. Fig.7.(d). shows a material composition comprising $1 \% \mathrm{Zn}$ of 
78at $\% \mathrm{Al}$ and the remainder of the other material. Fig.7 The use of $\mathrm{Zn}$ interlayer particles gives different effects on each joint $[15,17,19,25]$. The dispersion of $\mathrm{Zn}$ particles reacting with $\mathrm{Al}$ forms a reaction area. The direction of dispersion of $\mathrm{Zn}$ particles has different characteristics in each welding variation. The dwell time effect makes a difference on each joint. Fig.5 shows the wide-ranging Zn spread on each variation.

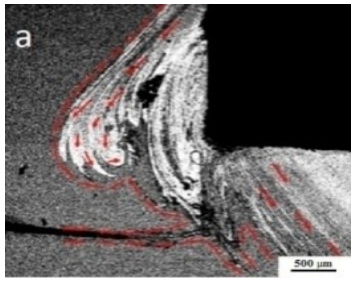

Fig.6.a Material Flow of Zn

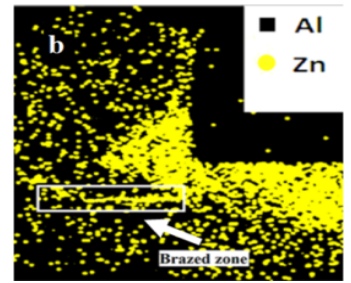

Fig.6.b mapping of $\mathrm{Zn}$

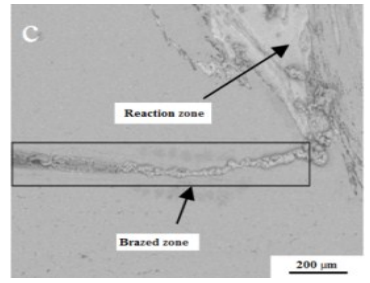

Fig.6.c Brazed zone

The effect of mechanical rotation on the tool and the heat input produces a reaction on the substrate. Fig.6.a $\mathrm{Zn}$ dispersion rate in welding results tends to decrease. The effect of dwell time results in a material that is softened longer so that the $\mathrm{Zn}$ particles tend toward the middle of the mortar. Fig.6.c shows the graph of bonded zone formation. Increased bonded zone due to mechanical pressure process of toll and heat input from friction effect. This process gives a longer time on $\mathrm{Zn}$ to soften and fill the gap in the joint. Fig.7.(f). XRD results in the transition region show the formation of $\mathrm{Al} \mathrm{Zn}$ and $\mathrm{Al}$.

a

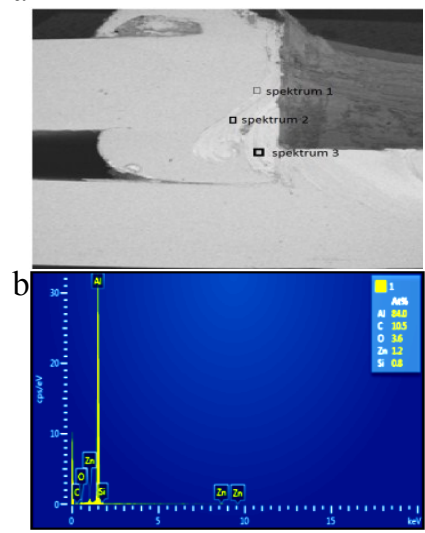

c

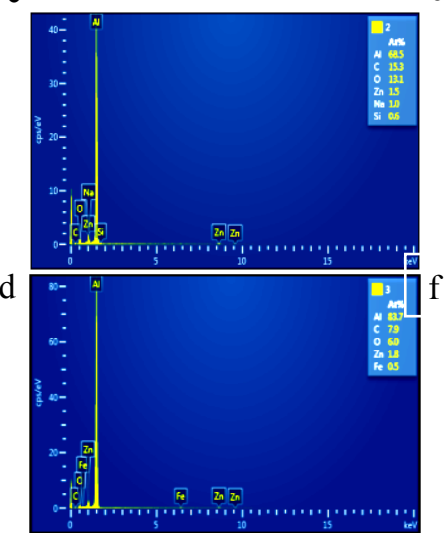

e

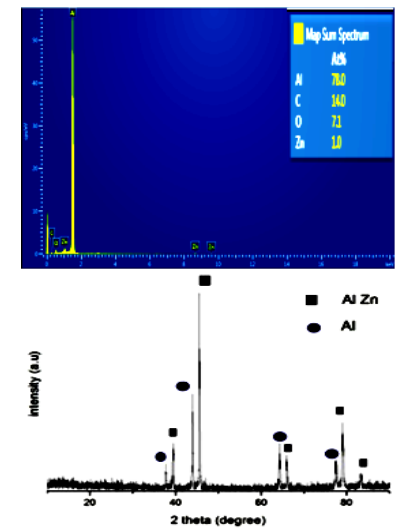

Fig.7.(a) EDS section. (b).spectrum 1. (c). spectrum 2. (d). spectrum 3. (e). EDS analysis on surface mapping. (f). XRD pattern of the interface between $\mathrm{Al}$ substrate and $\mathrm{Zn}$ interlayer

EDS analysis addresses the distribution of $\mathrm{Zn}$ interlayers[17, 19, 25]. Fig.7.a addresses the EDS section. The Zn spread differs in each section. Fig.7.b. shows the of $1.2 \% \mathrm{Zn}$ percentage of $\mathrm{Al} 84.0 \%$. Fig.7.c shows a of $1.5 \% \mathrm{Zn}$ percentage of AL 68.5\%. Fig.7.d shows a $1.8 \% \mathrm{Zn}$ percentage of $\mathrm{Al} 83.7 \%$. Zn material has increased toward the center of the stir zone.

\subsubsection{Distribution of $\mathrm{Zn}$ interlayer particles}

During the welding process occurs mechanical friction that causes heat. The work of the tool produces a mix between $\mathrm{Al}$ and $\mathrm{Zn}$. $\mathrm{Zn}$ substrate reacts with $\mathrm{Al}$ to form a material stream. Fig.6.b shows the extent to which $\mathrm{Zn}$ is spreading in the HAZ area. This process occurs the mechanism of pressure and rotation of the tool. An increase in the dwell time variable leads to a decrease in the length of $\mathrm{Zn}$. This is due to the tendency of $\mathrm{Zn}$ material to flow towards SZ. Fig.6.c shows the direction of the Zn substrate undergoing brazing process and closing the hook defect. The increased dwell time and pressure of the tool give the $\mathrm{Zn}$ substrate time flowing between the material gaps. 


\section{Conclusion}

In this study, the effect of $\mathrm{Zn}$ particle interlayer with dwell time variation on Mechanical Properties and Microstructure of Stir Spot Friction Welding Aluminum Alloy. The following conclusions were drawn.

(1) Highest tensile strength at FSSW joint without using Zn particle interlayer at dwell time $20 \mathrm{~s}$ with tensile strength of $2.7 \mathrm{kN}$. lowest tensile strength $2.5 \mathrm{kN}$ at $50 \mathrm{~s}$ dwell time. The level of violence in the SZ region with a value of $46.8 \mathrm{HV}$ the tensile strength of the joint without the $\mathrm{Zn}$ interlayer has a value of $2.7 \mathrm{kN}$.

(2) The highest tensile load at the FSSW joint with the Zn particle interlayer at the right time $20 \mathrm{~s}$ with a value of $3.8 \mathrm{kN}$. Tensile load increases with time. The highest hardness value in $\mathrm{SZ}$ with value $100.3 \mathrm{HV}$.

(3) Zn particles react with Al to form Al-Zn. Hook defects can be reduced so the joint strength increases. The addition of $\mathrm{Zn}$ interlayer reduces defects in the joint area. Area mapping $\mathrm{Zn}$ particle spreads around the joint area. $\mathrm{Zn}$ diffuses with $\mathrm{Al}$ formed the material and form of $\mathrm{Al} \mathrm{Zn}$.

\section{References}

1. Marcia McNutt, "Climate Change Impacts," vol. 341.

2. Y. Liu, Q. Sun, J. Liu, S. Wang, and J. Feng, "Effect of axial external magnetic fi eld on cold metal transfer welds of aluminum alloy and stainless steel," Mater. Lett., vol. 152, no. 2, pp. 29-31, 2015.

3. P. Xue, D. R. Ni, D. Wang, B. L. Xiao, and Z. Y. Ma, "Effect of friction stir welding parameters on the microstructure and mechanical properties of the dissimilar $\mathrm{Al}-\mathrm{Cu}$ joints," vol. 528, pp. 4683-4689, 2011.

4. J. M. Piccini and H. G. Svoboda, "Effect of pin length on Friction Stir Spot Welding ( FSSW ) of dissimilar Aluminum-Steel joints," Procedia Mater. Sci., vol. 9, pp. 504513, 2015.

5. H. Bisadi, A. Tavakoli, M. T. Sangsaraki, and K. T. Sangsaraki, "The influences of rotational and welding speeds on microstructures and mechanical properties of friction stir welded Al5083 and commercially pure copper sheets lap joints," J. Mater., vol. 43, pp. 80-88, 2013.

6. J. Peng, S. Fukumoto, L. Brown, and N. Zhou, "Image analysis of electrode degradation in resistance spot welding of aluminium," vol. 9, no. 4, pp. 331-336, 2004.

7. M. P. Mubiayi and E. T. Akinlabi, "Friction Stir Spot Welding between Copper and Aluminium : Microstructural Evolution," vol. II, 2015.

8. X. Liu, S. Lan, and J. Ni, "Analysis of process parameters effects on friction stir welding of dissimilar aluminum alloy to advanced high strength steel," Mater. Des., vol. 59, pp. 50-62, 2014.

9. K. P. Babu, S., Sankar, V. S., Ram, G. J., Venkitakrishnan, P. V., Reddy, G. M., \& Rao, "Microstructures and mechanical properties of friction stir spot welded aluminum alloy AA2014," J. Mater. Eng. Perform., vol. 71-84, 2013.

10. G. Buffa, P. Fanelli, L. Fratini, and F. Vivio, "Influence of joint geometry on micro and macro mechanical properties of friction stir spot welded joints," Procedia Eng., vol. 81, no. October, pp. 2086-2091, 2014.

11. W. Li, J. Li, Z. Zhang, D. Gao, W. Wang, and C. Dong, "Improving mechanical properties of pinless friction stir spot welded joints by eliminating hook defect," Mater. Des., vol. 62, pp. 247-254, 2014.

12. S. Z. Badarinarayan, H., Q. Yang, "Effect of tool geometry on static strength of friction stir spot-welded aluminum alloy," Int. J. Mach. Tools Manuf. 49.2, vol. 142-148, 2009. 
13. A. Buffa, G., Campanile, G., Fratini, L., \& Prisco, "Friction stir welding of lap joints: Influence of process parameters on the metallurgical and mechanical properties," Mater. Sci. Eng., vol. 19-26, 2009.

14. J. Y. Cao, M. Wang, L. Kong, and L. J. Guo, "Hook formation and mechanical properties of friction spot welding in alloy 6061-T6," J. Mater. Process. Technol., vol. 230, pp. 254-262, 2016.

15. M. Miyagawa, K., Tsubaki, M., Yasui, T., Fukumoto, "Spot Welding between Aluminum Alloy and Zn Coated Steel by Friction Stirring," J. Japan Inst. Light Met. 23, pp. 131-136, 2008.

16. J. M. Piccini and H. G. Svoboda, "Effect of the tool penetration depth in Friction Stir Spot Welding ( FSSW ) of dissimilar aluminum alloys," Procedia Mater. Sci., vol. 8, pp. 868-877, 2015.

17. R. Z. Xu, D. R. Ni, Q. Yang, C. Z. Liu, and Z. Y. Ma, “Journal of Materials Science \& Technology Pinless Friction Stir Spot Welding of Mg - 3Al - 1Zn Alloy with Zn Interlayer," vol. 32, pp. 76-88, 2016.

18. S. Lazarevic, S. F. Miller, J. Li, and B. E. Carlson, "Experimental analysis of friction stir forming for dissimilar material joining application," J. Manuf. Process., vol. 15, no. 4, pp. 616-624, 2013.

19. R. Z. Xu, D. R. Ni, Q. Yang, C. Z. Liu, and Z. Y. Ma, "Influencing mechanism of Zn interlayer addition on hook defects of friction stir spot welded $\mathrm{Mg}-\mathrm{Al}-\mathrm{Zn}$ alloy joints," vol. 69, pp. 163-169, 2015.

20. S. Hirasawa, H. Badarinarayan, K. Okamoto, T. Tomimura, and T. Kawanami, "Analysis of effect of tool geometry on plastic flow during friction stir spot welding using particle method," J. Mater. Process. Technol., vol. 210, no. 11, pp. 1455-1463, 2010.

21. P. Su, A. Gerlich, T. H. North, and G. J. Bendzsak, "Intermixing in Dissimilar Friction Stir Spot Welds," Metall. Mater. Trans. A, vol. 38, no. 3, pp. 584-595, 2007.

22. S. S. Yin, Y. H., Sun, N., North, T. H., \& Hu, "Influence of tool design on mechanical properties of AZ31 friction stir spot welds," Sci. Technol. Weld. Joining., 2013.

23. M. K. Bilici and A. I. Yükler, "Influence of tool geometry and process parameters on macrostructure and static strength in friction stir spot welded polyethylene sheets," Mater. Des., vol. 33, no. 1, pp. 145-152, 2012.

24. V. Malik, N. K. Sanjeev, H. S. Hebbar, and S. V. Kailas, "Investigations on the effect of various tool pin profiles in friction stir welding using finite element simulations," Procedia Eng., vol. 97, pp. 1060-1068, 2014.

25. R. Z. Xu, D. R. Ni, Q. Yang, C. Z. Liu, and Z. Y. Ma, "Influence of Zn interlayer addition on microstructure and mechanical properties of friction stir welded AZ31 Mg alloy," J. Mater. Sci., pp. 4160-4173, 2015.

26. P. Xue, D. R. Ni, D. Wang, B. L. Xiao, and Z. Y. Ma, "Effect of friction stir welding parameters on the microstructure and mechanical properties of the dissimilar $\mathrm{Al}-\mathrm{Cu}$ joints," Mater. Sci. Eng. A, vol. 528, no. 13-14, pp. 4683-4689, 2011.

27. A. Boucherit and R. Taillard, "AC PT," Mater. Des., vol. 124, pp. 87-99, 2017.

28. O. Lorrain, V. Favier, H. Zahrouni, and D. Lawrjaniec, "Understanding the material flow path of friction stir welding process using unthreaded tools," J. Mater. Process. Technol., vol. 210, no. 4, pp. 603-609, 2010.

29. Y. C. Lin, J. J. Liu, and J. N. Chen, "Material flow tracking for various tool geometries during the friction stir spot welding process," J. Mater. Eng. Perform., vol. 22, no. 12, pp. 3674-3683, 2013. 